\title{
Creating Algorithmic Symbols to Enhance Learning English Grammar
}

\section{Abolfazl Shirban Sasi ${ }^{1 *}$}

* Correspondence:

Pictologics@gmail.com

${ }^{1}$ Department of Applied Foreign

Languages, TransWorld University,

Taiwan

Received: 15 February 2018

Accepted: 19 April 2018

Published online: 20 June 2018

\begin{abstract}
This paper introduces a set of English grammar symbols that the author has developed to enhance students' understanding and consequently, application of the English grammar rules. A pretest-posttest control-group design was carried out in which the samples were students in two girls' senior high schools $(\mathrm{N}=135, \mathrm{P} \leq 0.05)$ divided into two groups: the Treatment which received grammar lessons with grammar symbols; and the Control which received grammar lessons without the symbols. The experiment lasted for 30 hours spanned in three months. The statistical test revealed a significant higher gain scores for the Treatment group. Thus, the author strongly recommends using these symbols (or similar ones with the same characteristics) at least for two reasons. Firstly, students do not have to memorize all of them (72 tense symbols and 50 other symbols). That is, with just a few rules to learn, and then applying the existing algorithm, other symbols are easily shaped. Secondly, using these symbols enables teachers and students to have a general idea as to what to expect next because several grammatical rules and formulae can be predicted in advance.
\end{abstract}

Keywords: abstraction, algorithm, grammar symbols, prediction, tenses 


\section{Introduction}

Thousands of years ago, Plato was the first to declare the 'Super-sensory world of ideas', that is to say, what we can perceive in this world is just a copy of a copy, or an imitation of imitation of what actually exists in another world (or perhaps our mind). For Plato, the mind was an immortal soul, the realm of all reason (Plato, 1961). Quoting Aristotle's remarks in Poetics, Gombrich (1972), explains that answering why imitation should give man pleasure, i.e. why we enjoy looking at perfect copies of things we find painful to behold in reality, Aristotle attributes this pleasure to man's inborn love of learning. In other words, "We find it appealing when we recognize things." (p.12). Hence, we have the term 'catharsis' in the Ancient Greek drama which means 'purification', 'emotional cleansing', or 'clarification.'

The current study tries to examine a similar perspective towards learning grammatical rules through some limited steps. Perhaps it is generally accepted that perceiving and then, implementing English grammar rules or principles play a crucial role in EFL/ESL situations. Proper language teaching and learning consist of knowing structural relations and the way in which they function in a certain language. The author believes that given the fact that English grammar is by nature very mathematical (i.e. there are finite rules with a few exceptions that make it possible to construct almost infinite number of English structures; e.g. sentences), then if we come up with a certain set of grammar symbols which follow some well-defined algorithms, this will eventually enhance the process of learning and internalizing the grammar rules in a faster and more reliable rate (both for students and teachers). Thus, in the present study, the author first introduces a list of symbols that he has developed, followed by an experimental design which discusses the immediate effects of learning these symbols in high school students achieving higher scores in standard typical English grammar tests. The author postulates that the viewpoints illustrated and the findings discussed in this paper can prove helpful to language practitioners and education policy makers.

\section{Review of the Literature}

\subsection{Abstract Bits of Knowledge and Symbols}

Donovan, Bransford, and Pellegrino (2003) argue that abstracted representations do not stay as isolated occurrences of events but become elements of larger, related events. Knowledge representations are built up through many opportunities for observing similarities and differences across diverse events. Halpern (2003) describes that we use our existing knowledge when we receive new information. Thus, the acquisition of knowledge is an active mental process. Each individual builds "extensive knowledge structures" that connect new ideas to what is known so that knowledge is always personal and somewhat idiosyncratic. Also, Stieglitz (1983) claims that previously acquired concepts and experiences help students in becoming successful in their language learning.

Ausubel (2000) believes that one major implication of the cognition is that the human psychological system, as being an information processing and storing mechanism, is shaped in a 
form that allows new ideas and information to be meaningfully absorbed and saved most effectively when appropriately relevant and typically more inclusive concepts or propositions are already available to play a subsuming role to provide anchorage to subordinate ideas. Vygotsky (1978) encourages educators to utilize the process of scaffolding as a means of gradually guiding the learner through experiences to increase knowledge and skills while striving to make connections to existing schemas. Langer (1957) hypothesises that language evolved according to our need to represent reality in symbols. Gombrich (1972) also remarks that there are astronomical numbers of stimuli that impose on us, and that whatever can be coded in symbols can also be retrieved and remembered with relative ease.

Buzan (2006) has a similar stand in simpler terminology. According to him, if human brain receives data which is rapidly forgotten or disliked, it will reject further data in that subject area. Thus, the more information is presented to the brain in the given subject, the more it will block that information and the less learning is likely to occur, often eventually blocking the information altogether. On the other hand, if the brain receives information in an organized and memorable matrix, each new bit of information will automatically link to the existing information, naturally building into patterns of recognition, understanding, and memory that are called knowledge. Elsewhere when elaborating on Mind Maps, Buzan (2005) also uses the metaphor "grappinghooks-on-memory" which according to him, will be created in order to attach new pieces of information into all the information already in there (the mind).

\subsection{The Role of Imagination in Shaping What We Know}

In his science-fiction journey (1989), “A Galactic Odyssey: A Journey in Eight Parts”, Gregory Benford - an astro-physicist, educator, and author - declares, "Some think language is the most distinctive feature of human beings, some favour these manipulative hands; personally, I believe it is our imagination." Also, if we like watching movies, we will never forget Steven Spielberg's Jurassic Park (1993). Nobody has seen dinosaurs, nobody has heard them, no one has felt them; however, Spielberg and his crew used their imagination in recreating these creeping creatures after 70 million years. As an example, it is interesting to notice that in order to design the roars of a Tyrannosaurus rex (T-rex), the sound effect team had successfully mixed the roars of a lion, with those of a crocodile, as well as a donkey's bray! The outcome was that amazing, startling, terrifying sound which shocked the viewers and made the producers millionaires!

There are several traces for imagination as to how languages were developed in the first place, as well as the pedagogical implications of such evidence in the realm of language teaching a few of which will be touched in here. According to Bronowski (1978), while nonhuman creatures appear capable of emotion, there is something unique to our ability to use emotions and imagery in the apprehension of complex ideas. According to Shlain (1998, p.45), images are mainly mental productions of the physical world of vision. From a bio-evolutionary point of view, using pictures to communicate occurred much longer prior to writing. He then asserts, "Before there was writing there were pictures. The desire to control the forces of nature led Paleolithic humans to create images of the world around them." 
According to Egan (2005), imagination is not peripheral to the essence of education; rather it can allow students opportunities to express themselves in 'the arts.' Egan believes that stimulating students' imaginations and encouraging their creativity is an important part of helping students to make connections between school activities and real-life situations. As Dondis (1973) suggests, developing our ability to see would mean enhancing our ability to understand a visual message, or even create one. It is an integral part of the communication process which engages all concerns in the fine art, applied art, subjective expression, and response to functional purpose. According to Gombrich (1972), we are logically free to categorize things in any number of ways and order them according to any quality they might share.

Mental imagery is also the foundation of Paivio's $(1971,1981)$ Dual Coding Theory. Some neurobiological pieces of evidence support the argument in dual coding theory that the brain maintains functionally independent verbal and nonverbal representational and processing systems. In other words, different parts of the brain are specialized for processing information verbally and nonverbally. Likewise, Freire (1979, p.105), postulates that man is able to reflect on himself and on the activity in which he is involved. Man can free himself from the world in order to find his place in it and with it. Freire further states, "To enter into reality means to look at it objectively, and apprehend it as one's field of action and reflection. It means to penetrate it more and more lucidly in order to discover the true interrelations between the facts observed."

\subsection{Usage of Symbols in Teaching English}

English grammar textbooks have used quite a number of visualization means like cartoons, caricatures, figures, real photos, etc. One might think of this usage as a continuum from highly concrete to highly abstract tools. At one end, we have the usage of real pictures like those used in Flynn, Rosenthal, Feigenbaum, and Butler (1998). Then, we have a mixture of real photos and cartoons like those in Kirn and Jack (1996), Mackay, Sherman, Forstrom, Pitt, and Velasco (2011), and Werner, Nelson, and Spaventa (1993). Then comes the usage of cartoons alone. This can be considered the most popular and frequent usage because there are many examples in the field, some of which are: Azar (1992), Eastwood (2002, 2013), Knepler (1990), Lites and Lehman (1990), Low (1986), Murphy and Altman (1989), Schoenberg (1994), and Seaton and Mew (2007).

A particular form of cartoons is the usage of stick figures such as those used in Allsop (1992). Then, we can see usage of diagrams or diagraming sentences which originally dates back to the late nineteenth century, developed by Alonzo Reed and Brainerd Kellogg (Haussamen, 2003). We can see examples of diagrams in Kaplan (1995) and Kolln and Funk (2012). The other tool is the usage of geometric shapes and lines. These images seem to be very useful when teaching English prepositions, types of nouns, and comparative or superlative adjectives. Some examples are: Allsop (1992), Bing (1989), Leech and Svartvik (1992), and Murphy (1993). And finally, there is the "abstract" usage of geometric shapes and lines at the end of the visualization continuum. This means that the graphs (or lines) used resemble the least to the real world. In other words, students should imagine the relation between the image and the idea (or grammatical rule) which it 
introduces. Some examples of this type can be seen in Allsop (1992), Leech and Svartvik (1992), and Murphy (1993). Table 1 encompasses a few of the above-mentioned visual aids.

Table 1. Samples of visual aids used in English grammar text books
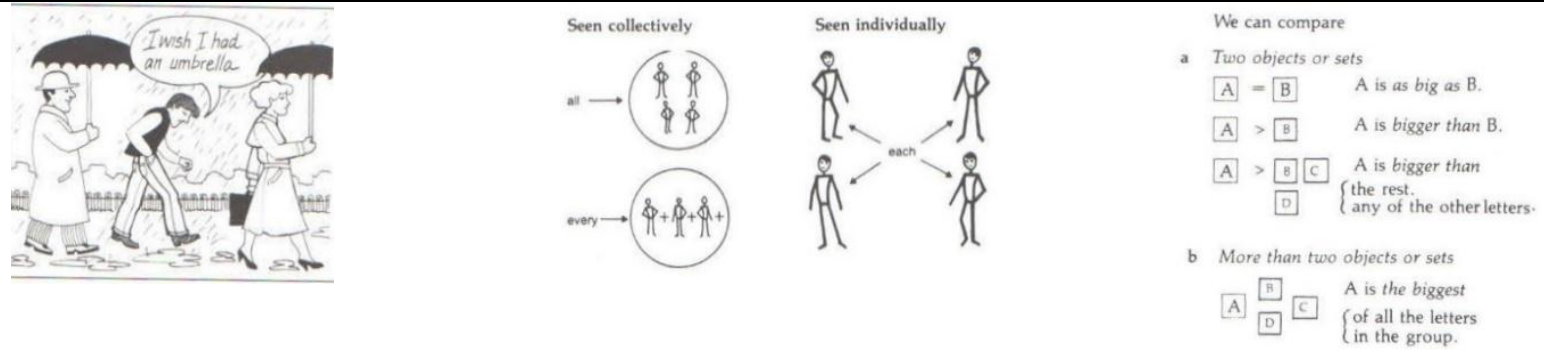

(Murphy \& Altman, 1989: 70)

(Allsop, 1992: 66)

(Allsop, 1992: 80)
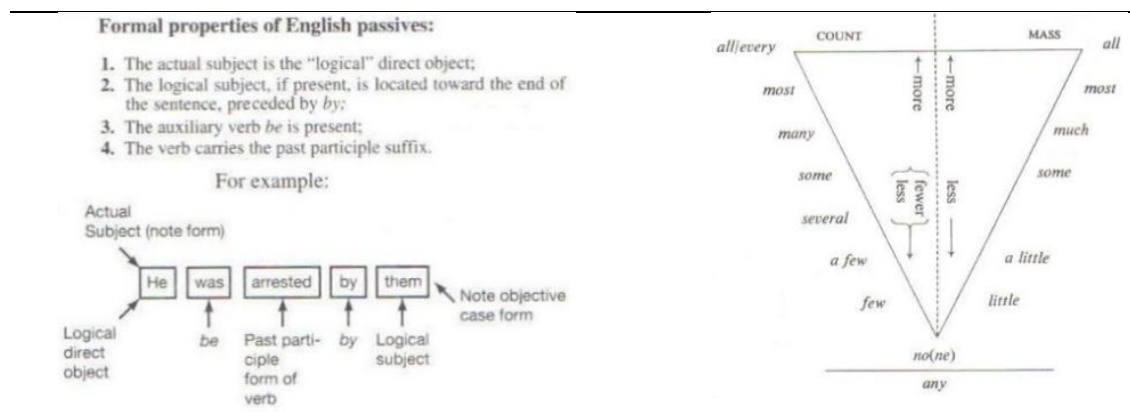

'nen' 'Now' 'rues'

(Kaplan, 1995: 180)

(Leech \& Svartvik, 1992: 51)

(Leech \& Svartvik, 1992: 139)

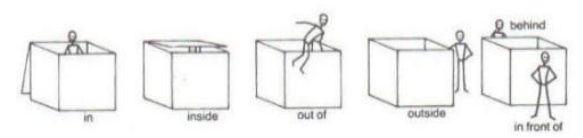

$\stackrel{\text { towards }}{\longrightarrow} \rightarrow-$ alhongh $\rightarrow$
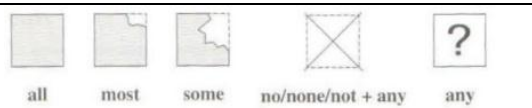

(Allsop, 1992: 109)

(Leech \& Svartvik, 1992: 88)

(Murphy, 1993: 148)

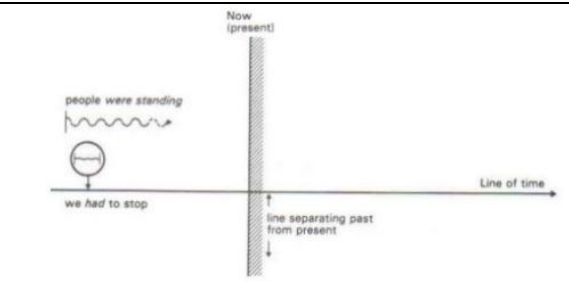

(Allsop, 1992: 157)

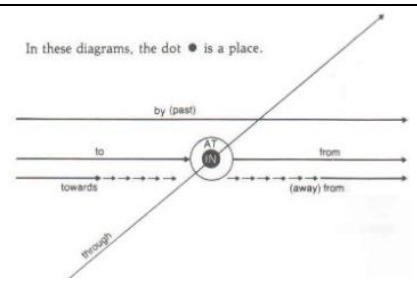
Here are four circles.
The first circle is the largest.
The next circle is smaller.
It is the second circle. It is the second circle.
The last circle is the smallest.

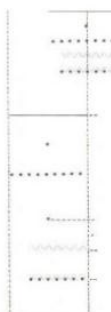

is the fourth circle.

(Allsop, 1992: 107)

(Bing, 1989: 187)

\subsection{The Montessori Grammar Symbols}

Although some of the examples mentioned above have a high level of abstraction, most probably, we cannot call them "symbols." The only true grammar symbols that the author has found in the related literature are those called, "Montessori Grammar Symbols" named after Maria Montessori, an Italian physician and educator. Tables 2 and 3 show these grammar symbols. 
Table 2. Basic Grammar Symbols

Article

Note. Data from http://www.montessorialbum.com/montessori/index. php?title=Grammar_Symbols (Retrieved July, 2017)

Table 3. Advanced Grammar Symbols

Proper
Noun
Abstract
Noun

Note. Data from http://www.montessorialbum.com/montessori/index. php?title=Grammar_Symbols (Retrieved July, 2017) 


\section{Author's Proposed English Grammar Symbols}

\subsection{Do We Even Need Grammar Symbols?}

In this section, we are going to have a glance at the English grammatical structures and patterns in a new way. Before anything, let me ponder upon the following analogy: Think of two different workshops. In the first one, the owner puts all his tools orderly on some shelves. Every tool has its own unique tag and place, and you never get confused in finding a specific one. On the other hand, in the second workshop, the owner has all the tools that the first owner had (perhaps, even more), yet he puts all his tools in a big bag instead of arranging them on the shelves. Now, who is more successful? The answer is certainly the first owner. It is true that the second owner has all the needed tools, but finding them in that big bag takes him a lot of time and energy. However, the first owner has spent a reasonable time and cost in installing the shelves before. In addition, most of the time, the second owner is not sure of what he has. He has to look into his bag thoroughly for a special tool, while the first owner can find his needed instruments easily just by taking a look over the shelves.

The same story is true about many learners of English. That is, a majority of the learners learn a vast range of information about English, but they do not know how to apply this information. Various titles, repetitious approaches to grammatical structures, and the feeling that they are not applicable, all will result in having a bag full of information. Consequently, students do not recognize which piece of linguistic data is useful to make a linguistic structure (written or oral). It is very important to notice that the number of major English language rules is limited. What makes these rules so difficult is that every learner has to practically know a good amount of these rules to be able to claim they know English. It is worth mentioning that since there is a complete and subtle coherence among language components, and their linking patterns (called grammar), advanced students must practice apparently simple language components (that is, what the elementary students have to learn at the beginning, and what the advanced ones are supposed to already know) on a regular basis.

Thus, in this section, we are going to present a particular strategy based on innovative grammar symbols in order to make a kind of mentally-leading learning procedure. To get familiar with these symbols, learners do not have to memorize all of them at all. Far from that, with knowing just the patterns (and the algorithms among them), the students will be able to predict them. This is somehow similar to the predictability power which exists in the Periodic Table of the elements. Please note that in the next sections of part 2, the author will use a "process instruction" language style for both simplicity and brevity. 


\subsection{The First Five Basic Symbols}

First of all, let us consider the following five very important symbols:

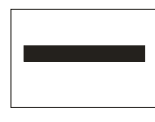

negative structures

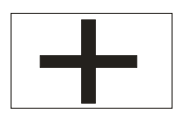

positive structures

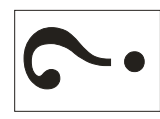

questions (all forms)

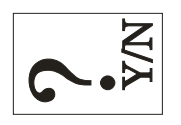

$\mathrm{Y} / \mathrm{N}$ questions

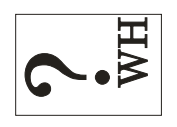

WH questions

As you can see, these signs are not new, and you already know them. So, this means that whenever a learner randomly picks one of these symbols, he or she should make an English structure (oral or written) accordingly.

\subsection{The Symbols for Tenses}

First of all, let us agree upon some presuppositions on the tenses as follows:

- Triangle shapes stand for the past, circle shapes stand for the present, and rhombus shapes stand for the future.

- If these shapes are not perfectly shaded; that is to say, if they are simple, then they will show the simple tenses.

- If these shapes are perfectly shaded; that is to say, if they are filled with color, then they will show the perfect tenses.

- If two similar shapes overlap each other partially, this shows progressive tenses.

- Then, combining the last two presuppositions, the partially overlapped shaded shapes show perfect progressive tenses.

Consequently, we will have the 12 English tenses as the following illustrated in Table 4.

Table 4. Symbols for 12 English tenses

\begin{tabular}{ll}
\hline \multicolumn{1}{c}{ Tense } \\
Simple
\end{tabular}

Now, remember the five signs introduced at the beginning which referred to negative structures, positive structures, all forms of questions, Y/N questions, and WH questions. We are going to use $(9 \times 6.5 \mathrm{~cm}$. $)$ cards in the classes. Then, if we just combine and incorporate these five symbols 
with the 12 symbols for the tenses in these cards and interpret each card diagonally from left to right, we will have 72 cards which are listed in Table 5.

Here is an example: We know that $\triangle$ is the symbol of the simple past, and $\square$ indicates negative structures. Thus $\triangle$ means "Make a negative structure in the simple past tense."

Table 5. The first set of the English grammar symbols (tenses)

\begin{tabular}{|c|c|c|c|c|c|c|}
\hline $\begin{array}{l}\text { Form } \\
\text { Tense }\end{array}$ & any structures & $\begin{array}{c}\text { only } \\
\text { positive } \\
\text { structures }\end{array}$ & $\begin{array}{l}\text { only negative } \\
\text { structures }\end{array}$ & $\begin{array}{c}\text { any } \\
\text { questions }\end{array}$ & $\begin{array}{c}\text { only } \\
\text { Y/N } \\
\text { questions }\end{array}$ & $\begin{array}{c}\text { only } \\
\text { WH } \\
\text { questions }\end{array}$ \\
\hline Simple Past & & & & & & \\
\hline $\begin{array}{l}\text { Simple } \\
\text { Present }\end{array}$ & & & & $?$ & & \\
\hline $\begin{array}{l}\text { Simple } \\
\text { Future }\end{array}$ & & & & & & \\
\hline Past Perfect & & & & & & \\
\hline $\begin{array}{l}\text { Present } \\
\text { Perfect }\end{array}$ & & 7 & & $?$ & & $?$ \\
\hline $\begin{array}{l}\text { Future } \\
\text { Perfect }\end{array}$ & & & & & & \\
\hline $\begin{array}{c}\text { Past } \\
\text { Progressive }\end{array}$ & & & $\Delta$ & & & 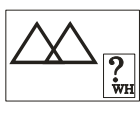 \\
\hline $\begin{array}{c}\text { Present } \\
\text { Progressive }\end{array}$ & & & & & & \\
\hline $\begin{array}{c}\text { Future } \\
\text { Progressive }\end{array}$ & & & & $\$$ ? & $>\left[\begin{array}{l}?_{\mathrm{Y} N} \\
\mid\end{array}\right.$ & ? ? ? ? \\
\hline
\end{tabular}

Past 


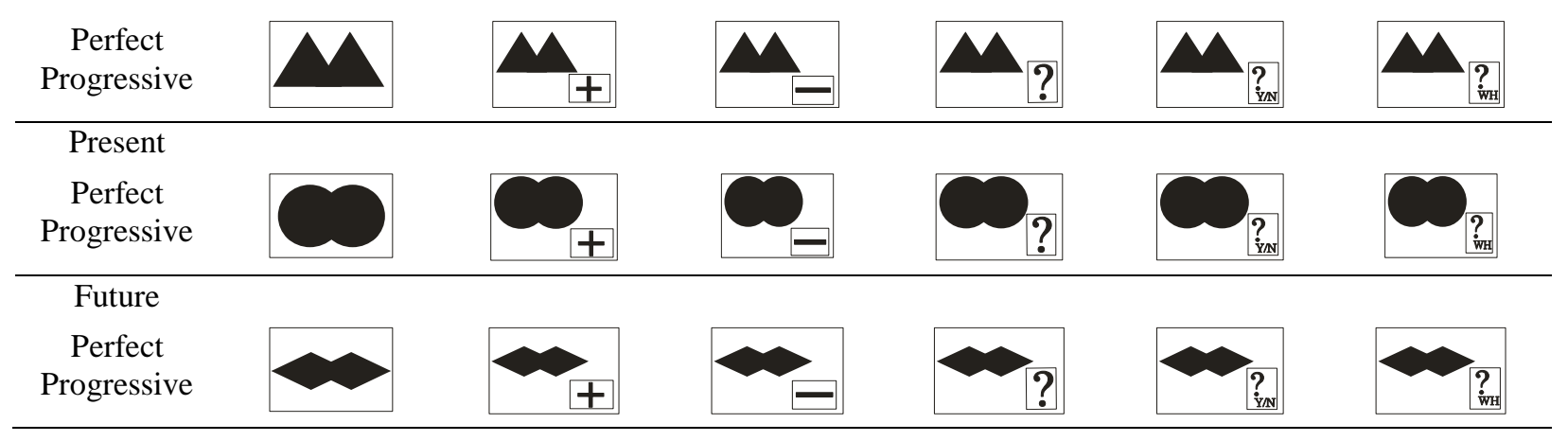

\subsection{The Symbols for English Grammar Functions Other Than Tenses}

Now that we have learnt about the Tense Symbols, let us have a look at some of the other signs and symbols which relate to some other grammatical patterns. Most probably, the logic behind each symbolic element is quite simple. I am also sure that you will soon discover the algorithm and learn all of symbols quickly.

Look at the following symbol:

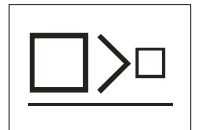
adjectives, or adjectives with two or more syllables, and according to the first symbol, we will have:

Now look at this symbol:
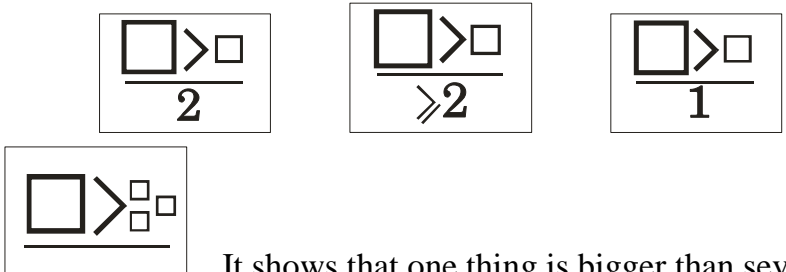

It shows that one thing is bigger than several things. As you have guessed, cost important usages of the Superlative Adjectives.

And again, based on the number of the syllables of the adjectives, we will have:
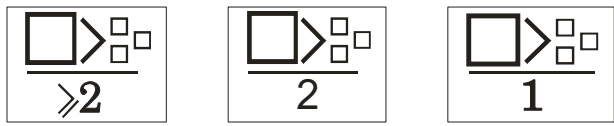

Applying a similar logic, we will have the following for as...as structures:

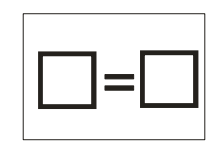

Now, let us look at the following:

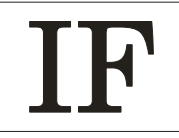

which symbolizes all types of the conditional sentences. And so for the conditionals type one, two, and three, we will have:
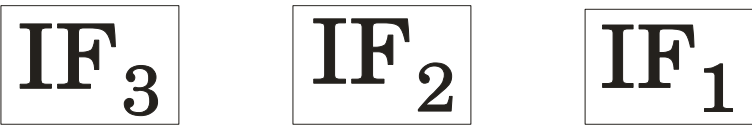
Also, we can have

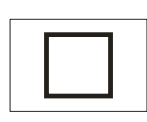
representing the active sentences, and

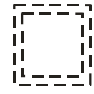
representing the passive structures.

So, we will have:

Also,

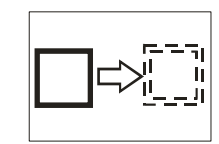

Change active structures to passive ones.

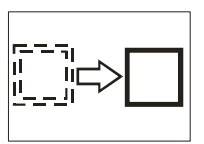

Change passive

structures to

active ones.

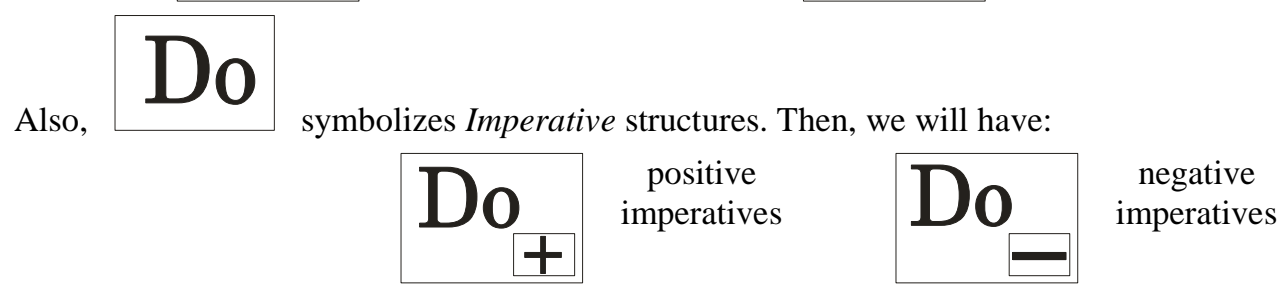

\subsection{General Notes}

Now that you have learnt the Grammar Symbols, let us pay attention to the following points:

* The sequence in which these symbols are introduced here does not necessarily match the order of learning them. It has been so in this paper to make a clear classification.

* Cards with more than one symbol on them are interpreted diagonally from left to right.

Example

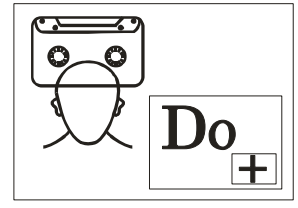

indirect reported speech

positive imperative sentences

* The tense symbols are printed in green, and the other grammar symbols are printed in red.

* You can often use two different categories of the grammar symbols (for example, a tense card and a non-tense one) together.

Example

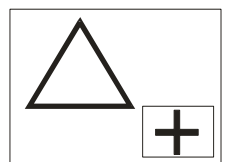

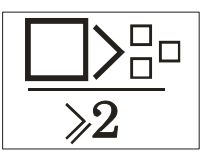

Make a positive structure in the simple past, and use a superlative adjective of two or more syllables.

As you can see, one of the cards above indicates superlative adjectives with two or more syllables, and the other card illustrates positive simple past tense.

* Depending on your English level, you can also use several grammar symbols simultaneously together with other props. Use your imagination and produce what you like. The following is an example from Shirban Sasi (2006, p. 216).

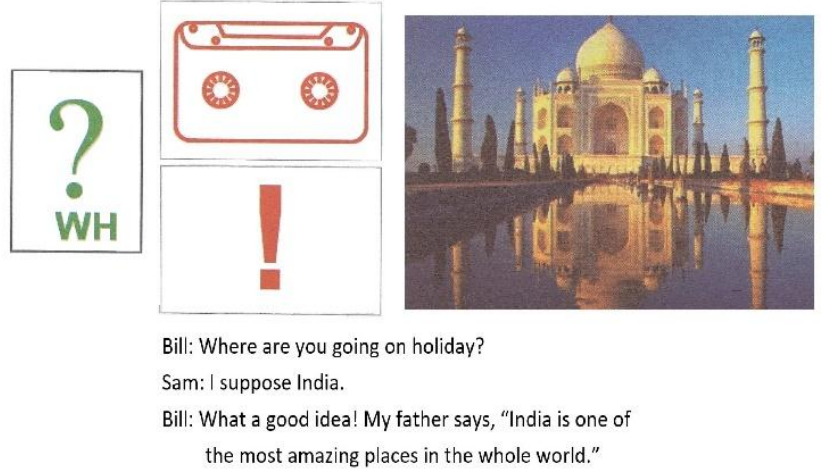


* Make sure to use each sign when you study the related lesson. Remember that you can easily learn the patterns existing among all the symbols in advance. However, when you want to apply them, learn the grammar first.

* The author introduced two types of workshop owners to you at the beginning of this chapter. Having learnt the Grammar Symbols: 1) You can classify your linguistic knowledge precisely, and 2) You can gain a general vision over what is there to be learnt later.

Now that you have been introduced the logic used for most of the symbols, let us have a look at them in Table 6. Hopefully, the algorithm used can be learnt quite quickly.

Table 6. The Second Set of the Grammar Symbols

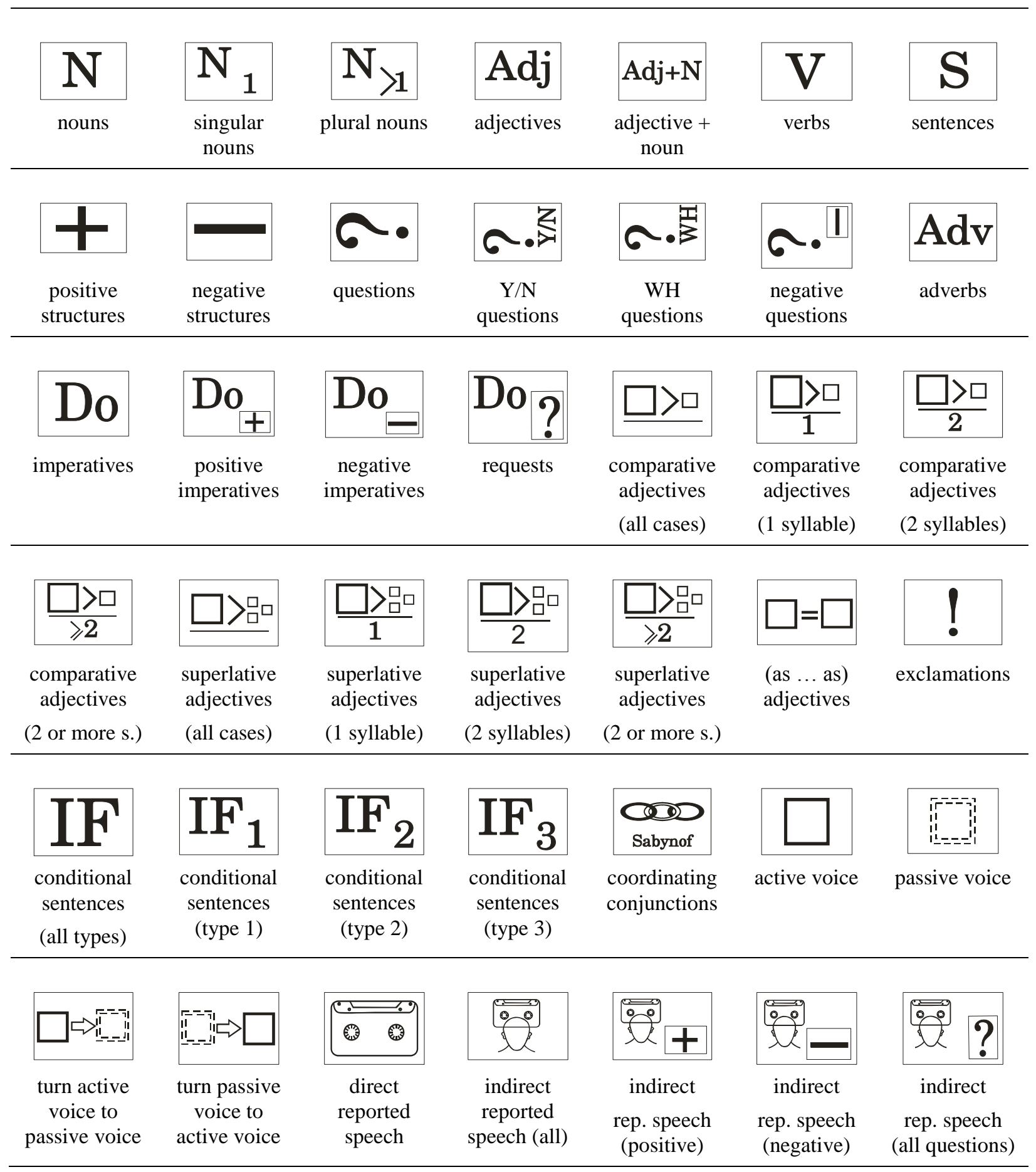




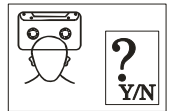

indirect

rep. speech

( $\mathrm{Y} / \mathrm{N}$

questions)

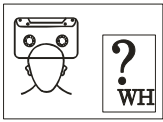

indirect

rep. speech

(WH

questions)

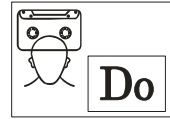

indirect

rep. speech

(all

imperatives)

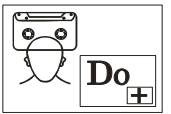

indirect rep. speech (pos. imp.)

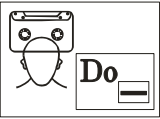

indirect

rep. speech

(neg. imp.)

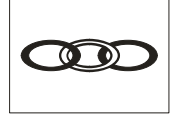

compound

structures

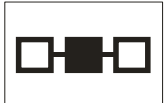

complex structures

\section{Material and Methods}

\subsection{Introduction}

The purpose of the data collected in this pre-test post-test control-group study was to investigate the effects of applying the Grammar Symbols on the grammar learning of Iranian senior highs school students.

\subsection{Design of the Study}

The pre-test post-test control-group design of the current study has the following characteristics as suggested by Creswell (2003, p.170):

- The experimental group A and the control group B were randomly assigned.

- Both groups took a pre-test and post-test.

- The experimental group received the new treatment (with grammar symbols).

- The control group received a conventional treatment (without grammar symbols).

Thus, the design can be shown as:

Group A

Group B
$\mathrm{R}$

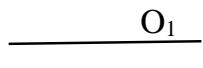

$\mathrm{R}$

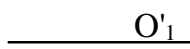

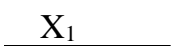

$\mathrm{X}_{2}$
$\mathrm{O}_{2}$

$\mathrm{O}_{2}^{\prime}$

Furthermore, it should be stressed here that in order to exclude the author from the treatment (to avoid researcher bias), the author had previously trained some teachers to teach the treatment course with the grammar symbols.

\subsection{Participants}

As part of a larger project (for more information, see Shirban Sasi, 2004, 2006, 2009, 2012, 2017, and 2018) approved by the English Department of the Ministry of Education (Tehran's Office), the author trained about 50 teachers to use these symbols and incorporate them in their lesson plans. For the current study, a pre-test-post-test control-group design was carried out. Two equally experienced female teachers were randomly assigned to two girls' senior high schools in the northwest area in Tehran. Each teacher taught two classes in each school. Totally, there were 74 students in the first school (the Treatment group), and 68 students in the second school (the Control group). However, only 71 students in the first school, and 64 students in the second school were present in both pre-test and post-test sessions, and thus were counted in the final analysis. The goal of both schools was to review and cover English grammatical rules in order to enable students to prepare for the university entrance multiple choice exams. The language of instruction was Persian, and the teaching method in both groups was a variety of Grammar Translation Method. The only difference in the teaching was that the teacher in the first high school also made use of the grammar symbols. Each session was 90 minutes, the classes were held twice a week for three months. When 
teaching, both teachers frequently introduced and used identical English multiple-choice test items in forms of handouts. These sample tests covered a variety of topics, the most important of which were: English main tenses, types of adjectives, question formats, conditional sentences, active/passive voice, coordination, conjunctive adverbs, and reported speech.

\subsection{Data Collection}

A 100-item multiple-choice grammar test was adapted and developed by the author based on the typical annual university entrance English tests. The test was meant to assess students' English grammar knowledge, and not their English vocabulary. Some of the questions used on this test are given in Appendix A. The pre-test took place one session prior to the lessons, and the post-test was administered one session immediately after the classes were over. Consequently, each individual student's gain score was calculated. Only correct answers were marked, therefore, unanswered test items or wrong answers were disregarded. Appendix B encompasses the scores of all the students in the two groups.

\subsection{Research Question and Hypothesis}

Based on the main objective of this experiment; that is, to examine any probable effects the usage of grammar symbols might have, the following research question, and hence, null hypothesis and directional hypothesis were shaped.

1. Is there any significant difference between the English grammar learning gain scores by the Iranian high school students who used the Grammar Symbols, and the English grammar learning gain scores by those who did not use Grammar Symbols?

Ho1- There is no significant difference between the English grammar learning gain scores by the Iranian high school students who used Grammar Symbols, and the English grammar learning gain scores by those who did not use Grammar Symbols.

$\mathrm{H}_{1}$ - The Iranian high school students who used the Grammar Symbols will have higher English grammar learning gain scores than those who did not use the Grammar Symbols.

\section{Data Analysis}

Since the statistical test used in this study was an independent samples t-test, the three assumptions of independence of observations, normality of the distribution of the scores, and homogeneity of the variances had to be met first. As stated earlier, the treatment and the control samples were randomly assigned into two different high schools. Also the two teachers had no idea as to what teaching material and techniques the other teacher was using. Thus, the independence of observations has been fully maintained in this study.

Then as for the normality of the distribution of the scores in the population is concerned, we should look at the descriptive statistics results including the K-S test as shown in Table 7. 
Table 7. Descriptive statistics for the gain scores

\begin{tabular}{|c|c|c|c|c|}
\hline & & & Statistic & Std. Error \\
\hline \multirow[t]{6}{*}{ Scores } & Mean & & 9.4148 & .42077 \\
\hline & \multicolumn{2}{|c|}{$\begin{array}{l}95 \% \text { Confidence IntervalLower Bound } \\
\text { for Mean }\end{array}$} & 8.5826 & \\
\hline & & Upper Bound & 10.2470 & \\
\hline & $5 \%$ Trimmed Mean & & 9.4630 & \\
\hline & Median & & 9.0000 & \\
\hline & Skewness & & -.202 & .209 \\
\hline
\end{tabular}

Table 7 shows that the mean of 9.41 is very close to the median of 9.00 in both groups. We can also look at the skewness statistics. Here, we can see that the skewness value of -.202 is small relative to the standard error of .209, so the skewness is not a problem here. Also, the K-S test of normality gives us a significant $p$ value of .20 suggesting that the distribution of gain scores is normal.

Then in order to determine whether the assumption of the homogeneity of the variances has been met, we should investigate the results of the independent samples t-test as shown in Table 8.

Table 8. Independent Samples Test for the gain scores

Levene's Test

for Equality

of Variances t-test for Equality of Means

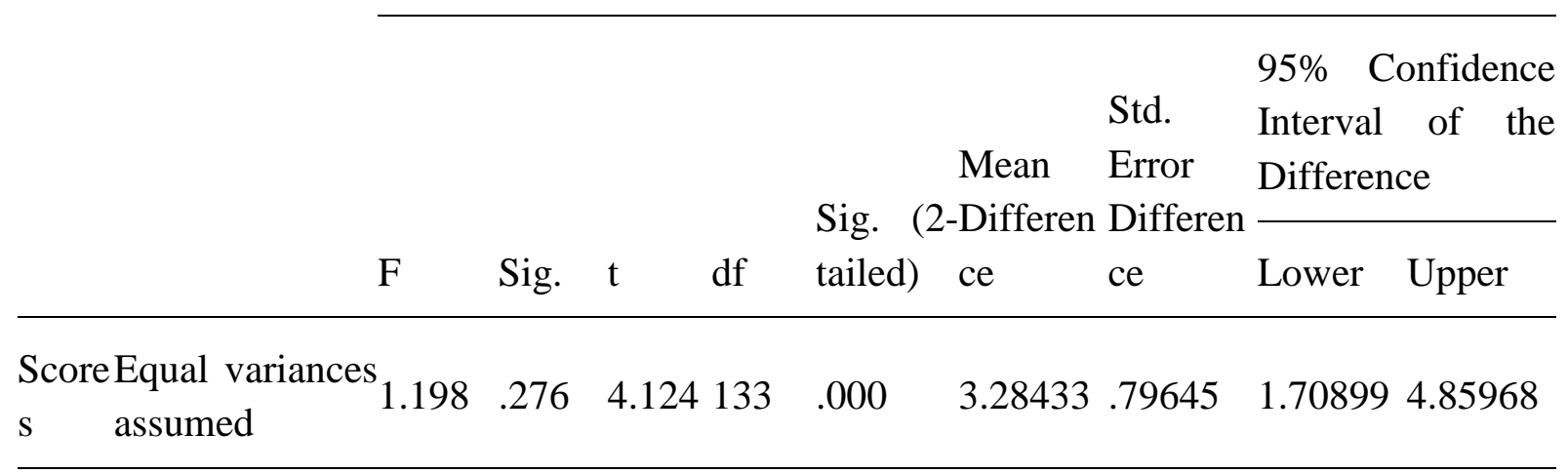


Equal variances

not assumed
$4.179 \begin{array}{ll}130.0 \\ 24^{0} .000\end{array}$

In Table 8, the significance value of the Levene's Test is .276 which is larger than .05. This means that the assumption of homogeneity of the variances of the scores for the population for this test has been met. Thus, we should use the first line in the table, which refers to "equal variances assumed." Therefore, in the current test, we have $\mathrm{t}(133)=4.124, p=.000$. As the $p=.000$ is less than the required cut-off value of .05 , the null hypothesis is rejected and we can conclude that there is a statistically significant difference in the English grammar gain score between the control and treatment groups. Moreover, as for the direction of the difference, we can see in Table 9 that the mean English grammar gain score of 10.97 for the treatment group is larger than the mean English grammar gain score of 7.68 for the control group. Thus, we can conclude that, as the alternative directional hypothesis conveys, those students who were taught with the Grammar Symbols have higher grammar gain score than those who did not use the grammar symbols.

Table 9. Group statistics

\begin{tabular}{llllll}
\hline & Group & $\mathrm{N}$ & Mean & \multicolumn{2}{l}{ Std. Deviation Std. Error Mean } \\
\hline Scores & 1.00 & 71 & 10.9718 & 5.13801 & .60977 \\
& 2.00 & 64 & 7.6875 & 3.96763 & .49595 \\
\hline
\end{tabular}

As the hypothesis has been explored, we need to calculate the effect size statistics which provides us with an indication of the magnitude of the differences between the two groups. A common way to do this is to calculate the eta squared. Since SPSS does not provide eta squared values for ttests, we should do the calculations on our own using the information provided in the output. The procedure for calculating and interpreting eta squared is by using the following formula as described by Pallant (2005):

Eta Squared $=\frac{t^{2}}{t^{2}+(N-1)}$

Eta squared $=\frac{4.124^{2}}{4.124^{2}+(71+64-2)}=.11$ 
According to Cohen (1988), the guidelines for interpreting this value are: $.01=$ small effect, $.06=$ moderate effect, $.14=$ large effect. Thus, we would claim that the effect size of .11 for this test is rather a large effect. Then, if we multiply this value by 100 , we can have the percentage, meaning that approximately 11 percent of the variance in English grammar gain score is explained by the two different treatments.

\section{Discussion}

In this article, the author has introduced some symbols in order to ease teaching and learning English grammar rules. As elaborated earlier, these symbols proved to be helpful because in the experiment, in two high schools, the students under instruction with these symbols scored better than the control group. Being "symbols" by definition means that the symbols do not directly relate to the entity they convey. That is the main difference between these grammar symbols and the other means of visualization used in the English grammar books, as briefly explained before.

The author assumes that one reason students might find it difficult to learn grammatical rules is because of their intangible titles. Thus, changing these titles to something much more touchable would be useful. As Aristotle states, students enjoy looking at perfect copies of things (symbols here) they find painful to behold in reality (the grammar rules). Moreover, the author's use of symbols in this article conforms to the arguments of Donovan, Bransford, and Pellegrino (2003) in that abstracted representations do not stay isolated. Then, the use of existing knowledge on the part of the students and teachers echo Halpern's (2003) and Stieglitz's (1983) findings. Also, as for the usage of algorithms in shaping the symbols, the author's suggestions comply with the description of cognition by Ausubel (2000). In terms of how students find it easier to memorize English grammar rules with the grammar symbols, one might recall Buzan $(2005,2006)$ in that these symbols might help construct better, and more comprehensible memorable matrixes. These symbols may as well provide students with the guiding scaffolding needed as argued by Vygotsky (1978).

Nonetheless, the symbols discussed in this paper vary from the Montessori symbols in the following ways:

- The Montessori symbols make use of the same geometric shapes (with a little difference in angle, size, and color) to convey different concepts.

- Color has been used in these symbols as a differentiating factor. It is true that colors add to the aesthetic quality of these symbols; however, they might be problematic in black and white copies, and also to color-blinded language learners.

- These symbols do not interact with one another.

- These symbols do not go any deeper; i.e. there is only one usage for each, and they do not explain details, relations, and range of use, etc.

- There is no predictability adhered to these symbols. 


\section{Conclusion}

The current study dealt with introducing a set of grammar symbols which the author has developed. An experiment regarding how high school students may benefit from them has also been described and discussed. Perhaps what makes the author's symbols useful is both the simplicity of learning them (not memorizing them), and the fact that the algorithms used are quite conceivable. Ironically, though, the author believes that even his long list of grammar symbols presented in this article is neither enough nor conclusive. These symbols have covered a lot of topics, yet not all of the topics pertinent to the English grammar. In other words, for different contexts such as various learners' age, background, nationality, needs, purpose of learning, etc., we can come up with new symbols and new algorithms. As an example, please look at an alternative set of symbols for the English grammar tenses in Table 10 below. The author also postulates that similar algorithms might be employed to facilitate learning grammar rules of other languages as well. Finally, the author recommends the following topics for relevant future researches in the field:

- Studying larger number of high school participants of both genders,

- Examining the effects of these grammar symbols on EFL/ESL university students,

- Investigating probable differences between males and females in using grammar symbols,

- Exploring the effects of these grammar symbols on different age, and/or English proficiency levels,

- Observing other language learners using these symbols in the other cities in Iran, or in other countries,

- Exploring the adaptability of teaching these grammar symbols along with conventional methods, and

- Soliciting teachers who have used these grammar symbols, and those who are willing to.

Table 10. Alternative Symbols for 12 English tenses

\begin{tabular}{|c|c|c|c|}
\hline Tense & Past & Present & Future \\
\hline Simple & & & $\longrightarrow$ \\
\hline Perfect & & & 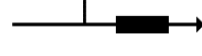 \\
\hline Progressive & & $\underset{\}}{\longrightarrow}$ & $\stackrel{\leftrightarrow}{\longrightarrow}$ \\
\hline $\begin{array}{l}\text { Perfect } \\
\text { Progressive }\end{array}$ & & $\longrightarrow$ & \\
\hline
\end{tabular}




\section{References}

Allsop, J. (1992). Students’ English grammar. London: Prentice Hall International (UK) Limited.

Ausubel, D. P. (2000). The acquisition and retention of knowledge: a cognitive view. Dordrecht: Kluwer Academic Publishers.

Azar, B. S. (1992). Fundamentals of English grammar (2nd ed). New Jersey: Regents/Prentice Hall.

Benford, G. (1989). A galactic Odyssey: A journey in eight parts. [A TV Series, produced by Japan National Broadcasting.]

Bing, J. M. (1989). Grammar guide: English grammar in context. New Jersey: Prentice-Hall, Inc.

Bronowski, J. (1978). The origins of knowledge and imagination. New Haven, CT: Yale University Press.

Buzan, T. (2005). Mind map handbook. London: Thorsons.

Buzan, T. (2006). Master your memory. Essex: BBC Active.

Cohen, J. (1988). Statistical power analysis for the behavioral sciences. Hillsdale, NJ: Erlbaum.

Creswell, J. W. (2003). Research design: qualitative, quantitative and mixed methods approaches (2nd ed.). London: Sage Publications.

Dondis, D. A. (1973). A primer of visual literacy. Cambridge, MA: MIT Press.

Donovan, M. S., Bransford, J. D., \& Pellegrino, J. W. (eds). (2003). How people learn: brain, mind, experience, and School. Washington, D.C.: National Academy Press.

Eastwood, J. (2002). Oxford guide to English grammar. Oxford: Oxford University Press.

Eastwood, J. (2013). Oxford practice grammar intermediate. Oxford: Oxford University Press.

Egan, K. (2005). An imaginative approach to teaching. San Francisco: Jossey-Bass.

Flynn, K. F., Rosenthal, M., Feigenbaum, I., \& Butler, L. (1998). Connect with English: grammar guide 2. New York: McGraw-Hill.

Freire, P. (1979d). A desmistificacao da conscientizacao (conferencia), in C. A. Torres (1979a), pp. $105-118$.

Gombrich, E. H. (1972). Art and illusion: A study of the psychology of pictoria representation. Princeton, NJ: Princeton University Press.

Halpern, D. F. (2003). Thought \& knowledge: An introduction to critical thinking (4 ${ }^{\text {th }}$ ed) London: Lawrence Erlbaum Associates, Publishers.

Haussamen, B. (2003). Grammar alive! : A guide for teachers. Illinois: National Council of Teachers of English.

Kaplan, J. P. (1995). English grammar: principals and facts. New Jersey: Prentice-Hall International, Inc.

Kirn, E., \& Jack, D. (1996). A communicative grammar (3 $3^{\text {rd }}$ ed). USA: McGraw-Hill.

Knepler, M. (1990). Grammar with a purpose: a contextualized approach. Boston: Heinle \& Heinle Publishers.

Kolln, M., \& Funk, R. (2012). Understanding English grammar ( $9^{\text {th }}$ ed). New Jersey: Pearson Education, Inc.

Langer, S. (1957). Philosophy in a new key: A study in the symbolism of reason, rite and art. Cambridge, MA: Harvard University Press.

Leech, G., \& Svartvik, J. (1992). A communicative grammar of English. England: Longman. 
Lites, E., \& Lehman, J. (1990). A pre-intermediate grammar. New Jersey: Prentice-Hall, Inc.

Low, O. (1986). Grammar for everyday use. London and Glasgow: Collins ELT.

Mackay, S., Sherman, K. D., Forstrom, J., Pitt, M., \& Velasco, S. (2011). Excellent English 2: language skills for success. New York: McGraw-Hill.

Murphy, R., \& Altman, R. (1989). Grammar in use: reference and practice for intermediate students of English. Cambridge: Cambridge University Press.

Murphy, R. (1993). Basic grammar in use. Cambridge: Cambridge University Press.

Paivio, A. (1971). Imagery and verbal processes. New York: Rinehart and Winston Publishers.

Paivio, A., \& Begg, I. (1981). Psychology of language. Englewood Cliffs, NJ: Prentice-Hall.

Pallant, J. F. (2005). SPSS survival manual: a step by step guide to data analysis using SPSS. Sydney, Ligare.

Plato, P. (1961). Republic. In Hamilton, E., \& Cairns, H. (eds. and trans) Plato: The collected dialogues. Princeton, NJ: Princeton University Press, pp. 575-844.

Schoenberg, I. E. (1994). Focus on grammar: a basic course for reference and practice. New York: Addison-Wesley Publishing Company, Inc.

Seaton, A., \& Mew, Y. H. (2007). Basic English grammar for English language learners. CA: Saddleback Educational Publishing.

Shirban Sasi, A. (2004). Pictologics system, elementary: textbook. Tehran: Peyk-e Zaban Publishers.

Shirban Sasi, A. (2006). Pictologics system, intermediate: textbook. Tehran: Peyk-e Zaban Publishers.

Shirban Sasi, A. (2009) Improving imagination in EFL/ESL classes: The case of PICTOLOGICS. In: Asian EFL Journal 7th International Conference, 10-11 April, 2009, Pusan, South Korea.

Shirban Sasi, A. (2012). The effects of applying Pictologics (PLS) method on English vocabulary learning by Malaysian year six primary school students. Unpublished Ph. D. thesis, University Sains Malaysia, Malaysia. Willingham

Shirban Sasi, A. (2017). Pictotherapy: Training high school teachers in quake-stricken areas to rethink communication skills. Journal of Educational Research and Review, 5(5), 79-89. sciencewebpublishing.net/jerr/archive/2017/September/Abstract/Sasi.htm

Shirban Sasi, A. (2018). Pictologics: A teaching method by imaginative usage of pictures. MEXTESOL Journal, 42(1), 1-11.

Shlain, L. (1998). The alphabet and the goddess: The conflict between word and image. New York: Viking.

Stieglitz, E. L. (1983). A practical approach to vocabulary reinforcement. ELT Journal, 37(1), 71-75. https://doi.org/10.1093/elt/37.1.71

Vygotsky, L. S. (1978). Mind in society: The development of higher psychological processes. (Cole M and Scribner S, trans). Cambridge, MA: Harvard University Press.

Werner, P. K., Nelson, J. P., \& Spaventa, M. (1993). Interactions access: a communicative grammar. New York: McGraw-Hill.

http://www.montessorialbum.com/montessori/index.php?title=Grammar_Symbols (retrieved on 12 July, 2017) 
Appendix A: A sample of the English grammar pretest and posttest used in this research. (The item numbers correspond to the real number of the item in the original test.)

5- Her brother doesn't smoking.
a) like
c) liking
b) likes
d) liked

10- I _ _ the DVD back to Jack after I watching it.
a) take / finished
c) took / had finished
b) have taken / have finished
d) had taken / finished

15- I'm sorry, I can't help you just now. I lunch.
a) will cook
c) cook
b) am cooking
d) cooked

20- I'll be ready in minutes.
a) a lot
c) much
b) a little
d) a few

25- I think that my house is yours!
a) dirty
c) the dirtiest
b) dirtier than
d) dirtier

30- If Sarah ___ a watch, she ___ always late.
a) will have / won't be
c) has / is
b) had / isn't
d) had / wouldn't be

35- I like Reza, I don't like his brother.
a) and
c) nor
b) but
d) so

40- $\quad$ The teachers in my school a new supervisor.
a) have been elected
c) has elected 

b) have elected
d) was elected

45- He gave her a CD player stopped working after three weeks.
a) that
c) when
b) who
d) where

50- I always take a shower ___ I go to bed.
a) when
c) before
b) if
d) until

55- We began about our wedding plan a few months ago.
a) talked
c) talking
b) talks
d) talk

60- Mary ___ work very hard because of the important exam she has next week.
a) am having
c) has to
b) had to
d) have to

65- $\quad$ There were not people at the stadium yesterday.
a) many
c) much
b) a few
d) a little

70- Afrikaans is in South Africa.
a) speaks
c) spoke
b) spoken
d) be spoken

75- He___ the address, so I helped him out by a map.
a) forgets
c) forget
b) has forgotten
d) had forgotten

80- We met at the train station. I'd rather we here.
a) meet
c) would meet
b) met
d) had met 
85- I can't imagine how save the endangered species.
a) they are going to
c) did they
b) do they
d) are they going to

90- Her hair looked as if it
a) has just been dyed
c) had just been dyed
b) has been cutting
d) needs cutting

95- He didn't have enough money, he couldn't buy that motorcycle.
a) moreover
c) however
b) because
d) consequently

100- I don't enjoy my job as much as I when I first started it.
a) was
c) did enjoy
b) did
d) done 
Appendix B: English grammar scores in pretest-posttest by the two groups (out of 100)

\begin{tabular}{|c|c|c|c|c|c|c|c|c|c|c|c|c|c|c|c|}
\hline \multirow[b]{2}{*}{ No. } & \multirow[b]{2}{*}{ Pre } & \multicolumn{6}{|c|}{ Treatment Group } & \multicolumn{8}{|c|}{ Control Group } \\
\hline & & Post & GS & No. & Pre & Post & GS & No. & Pre & Post & GS & No. & Pre & Post & GS \\
\hline 1 & 39 & 48 & 9 & 37 & 48 & 65 & 17 & 1 & 32 & 41 & 9 & 33 & 45 & 52 & 7 \\
\hline 2 & 51 & 63 & 12 & 38 & 44 & 54 & 10 & 2 & 39 & 44 & 5 & 34 & 45 & 54 & 9 \\
\hline 3 & 54 & 57 & 3 & 39 & 46 & 54 & 8 & 3 & 30 & 37 & 7 & 35 & 31 & 33 & 2 \\
\hline 4 & 43 & 51 & 8 & 40 & 33 & 46 & 13 & 4 & 27 & 43 & 16 & 36 & 35 & 39 & 4 \\
\hline 5 & 30 & 40 & 10 & 41 & 18 & 28 & 10 & 5 & 40 & 52 & 12 & 37 & 23 & 30 & 7 \\
\hline 6 & 29 & 38 & 9 & 42 & 25 & 42 & 17 & 6 & 19 & 25 & 6 & 38 & 21 & 32 & 11 \\
\hline 7 & 44 & 53 & 9 & 43 & 29 & 31 & 2 & 7 & 14 & 20 & 6 & 39 & 48 & 54 & 6 \\
\hline 8 & 33 & 47 & 14 & 44 & 36 & 46 & 10 & 8 & 39 & 43 & 4 & 40 & 14 & 29 & 15 \\
\hline 9 & 35 & 36 & 1 & 45 & 34 & 47 & 13 & 9 & 52 & 49 & -3 & 41 & 40 & 47 & 7 \\
\hline 10 & 39 & 52 & 13 & 46 & 21 & 41 & 20 & 10 & 47 & 54 & 7 & 42 & 37 & 51 & 14 \\
\hline 11 & 52 & 63 & 11 & 47 & 25 & 38 & 13 & 11 & 29 & 33 & 4 & 43 & 23 & 40 & 17 \\
\hline 12 & 45 & 49 & 4 & 48 & 50 & 69 & 19 & 12 & 15 & 29 & 14 & 44 & 19 & 32 & 13 \\
\hline 13 & 47 & 53 & 6 & 49 & 32 & 43 & 11 & 13 & 28 & 34 & 6 & 45 & 42 & 42 & 0 \\
\hline 14 & 23 & 35 & 12 & 50 & 37 & 47 & 10 & 14 & 51 & 59 & 8 & 46 & 37 & 45 & 8 \\
\hline 15 & 32 & 42 & 10 & 51 & 29 & 24 & -5 & 15 & 53 & 61 & 8 & 47 & 33 & 36 & 3 \\
\hline 16 & 19 & 29 & 10 & 52 & 24 & 35 & 11 & 16 & 31 & 39 & 8 & 48 & 52 & 57 & 5 \\
\hline 17 & 47 & 40 & -7 & 53 & 20 & 33 & 13 & 17 & 32 & 39 & 7 & 49 & 20 & 29 & 9 \\
\hline 18 & 46 & 51 & 5 & 54 & 38 & 53 & 15 & 18 & 38 & 44 & 6 & 50 & 17 & 31 & 14 \\
\hline 19 & 50 & 60 & 10 & 55 & 42 & 52 & 10 & 19 & 29 & 36 & 7 & 51 & 32 & 35 & 3 \\
\hline 20 & 44 & 57 & 13 & 56 & 44 & 65 & 21 & 20 & 43 & 54 & 11 & 52 & 49 & 58 & 9 \\
\hline 21 & 42 & 55 & 13 & 57 & 49 & 64 & 15 & 21 & 46 & 50 & 4 & 53 & 24 & 28 & 4 \\
\hline 22 & 24 & 32 & 8 & 58 & 43 & 53 & 10 & 22 & 44 & 56 & 12 & 54 & 25 & 36 & 11 \\
\hline 23 & 43 & 60 & 17 & 59 & 37 & 42 & 5 & 23 & 49 & 52 & 3 & 55 & 19 & 27 & 8 \\
\hline 24 & 45 & 58 & 13 & 60 & 49 & 60 & 11 & 24 & 28 & 37 & 9 & 56 & 47 & 54 & 7 \\
\hline 25 & 40 & 55 & 15 & 61 & 18 & 39 & 21 & 25 & 19 & 26 & 7 & 57 & 41 & 50 & 9 \\
\hline 26 & 33 & 47 & 14 & 62 & 21 & 33 & 12 & 26 & 24 & 29 & 5 & 58 & 26 & 34 & 8 \\
\hline 27 & 48 & 60 & 12 & 63 & 25 & 32 & 7 & 27 & 24 & 28 & 4 & 59 & 30 & 34 & 4 \\
\hline 28 & 42 & 55 & 13 & 64 & 32 & 46 & 14 & 28 & 31 & 40 & 9 & 60 & 33 & 39 & 6 \\
\hline
\end{tabular}




\begin{tabular}{llll|llll|llll|llll}
\hline $\mathbf{2 9}$ & 17 & 34 & 17 & $\mathbf{6 5}$ & 34 & 49 & 15 & $\mathbf{2 9}$ & 43 & 49 & 6 & $\mathbf{6 1}$ & 38 & 47 & 9 \\
\hline $\mathbf{3 0}$ & 52 & 59 & 7 & $\mathbf{6 6}$ & 40 & 51 & 11 & $\mathbf{3 0}$ & 18 & 31 & 13 & $\mathbf{6 2}$ & 36 & 41 & 5 \\
\hline $\mathbf{3 1}$ & 44 & 54 & 10 & $\mathbf{6 7}$ & 37 & 43 & 6 & $\mathbf{3 1}$ & 10 & 27 & 17 & $\mathbf{6 3}$ & 41 & 45 & 4 \\
\hline $\mathbf{3 2}$ & 47 & 60 & 13 & $\mathbf{6 8}$ & 29 & 48 & 19 & $\mathbf{3 2}$ & 47 & 56 & 9 & $\mathbf{6 4}$ & 29 & 37 & 8 \\
\hline $\mathbf{3 3}$ & 24 & 43 & 19 & $\mathbf{6 9}$ & 30 & 41 & 11 & & & & & & & \\
\hline $\mathbf{3 4}$ & 30 & 41 & 11 & $\mathbf{7 0}$ & 37 & 47 & 10 & & & & & & & \\
\hline $\mathbf{3 5}$ & 33 & 44 & 11 & $\mathbf{7 1}$ & 23 & 35 & 12 & & & & & & & \\
\hline $\mathbf{3 6}$ & 51 & 58 & 7 & & & & & \multicolumn{1}{c}{} \\
\hline
\end{tabular}

